\title{
A case study on effect of integrative medicine with combination of hrudaydhara (heart stimulation) and yoga therapy on ejection fraction of patient with history of hypertension
}

\author{
Satyam Tripathi ${ }^{1 *}$ Mika Azuma² and Rohin Vinayak ${ }^{3}$ \\ 1,2Union Yoga Ayurveda Singapore \\ ${ }^{3}$ Government Multi Speciality Hospital, Sector 16, Chandigarh, India
}

\section{KEY WORDS}

Cardiovascular disease

Hrudaydhara

MSRT

Sun salutation
*Corresponding Author:

Satyam Tripathi, MD

Union Yoga Ayurveda Singapore

Contact no: $+65-832166170$

E-mail: ayur.st@gmail.com

\begin{abstract}
Today, cardiovascular disease has become a global health issue owing to high-stress in personal and professional environments and adverse lifestyle changes with neglected diet and decreased physical activity. Ayurveda and Yoga aim not only to treat diseases but to also reinforce measures to promote health and well-being. Holistic approaches in these two sciences can be used in an effective way to improve cardiovascular health. A blend of Yoga practices and Ayurveda therapy is quintessentially useful for both the mind and body. Sun Salutation and Mind Sound Resonance Technique (MSRT) meditation work on calming the mind and allow the body to transition into a high energy state for moderate exercise. This is followed ultimately by Hrudaydhara of Ayurveda which focuses on relaxing the intercostal and cardiac muscle which in turn reduces chest discomfort of the patient and eventually improves the ejection fraction of the heart. This shows evidence that integrating yoga and ayurvedic practices with conventional medicine can be a collaborative approach while managing cardiovascular ailments.
\end{abstract}

doi: $10.38205 /$ imcr.020250

\section{Introduction}

Cardiovascular disease (CAD) refers to number of conditions such as coronary artery disease which can result in myocardial infarction, angina, stroke and heart failure. According to WHO, CADs are the number one cause of death globally, with an estimated mortality of 17.9 million each year (1). Statistics by Singapore heart foundation suggest that in Singapore, 17 people die from CAD daily (2). Another statistical study done by the Ministry of Health Singapore, shows that CAD accounted for $29.2 \%$ of all deaths in 2018 out of which $18.1 \%$ of patients had coronary artery disease (2). The survey suggests that 1 out of 3 deaths in Singapore are due to CAD. Looking at ethnical variations in prevalence of CAD, South Asian people tend to have a higher risk because of anatomically narrow blood vessels. In a case study of "Coronary heart disease risk factors in South Asian men subgroup, compared with native British men" done by Nish Chaturvedi, it has been shown that higher prevalence of insulin resistance and its risk factors in Indian ethnics accounts for a high predisposition to develop CAD (3). In Ayurve$\mathrm{da}$, heart disease is described as Hridroga. "Hrid" means heart and "roga" means disease. When we look at Samprapti, Hridroga is considered as Tri dosha imbalance (4). Excess avalambaka kapha (the diameter and elasticity of the blood vessels) (5) induces exaggerated contractility of the heart, while aggravated vyana vayu (the forces that expel the blood out of the heart) (5) leads increased speed of blood flow and increases the force of ejection of blood from heart. These events result in forceful expulsion of blood through blood vessels and increase resistance in vessels causing high blood pressure and symptoms of CAD (5). Ayurveda therapy has a five-step procedure called Panchakarma, and it has been used to treat various diseases including CAD. The effectiveness of Panchakarma for CAD has been demonstrated as an add-on therapy to Ayurvedic herbal medicine in a study (6). Panchakarma for cardiovascular system can be called as a form of Heart failure reversal therapy (HFRT), designed to enhance cardiorespiratory fitness of chronic heart failure patients while using techniques such as Snehana, Swedana, Hridaydhara, and Basti $(6,7)$.

Yoga is an integrated system of connecting the body, mind and spirit which significantly results in healthier bodily functions. Recent study suggests yoga and meditation is useful in primary and secondary prevention of CAD as it regulates risk factors such as stress and blood pressure (8). Therefore, an integrated yoga and ayurveda therapy is beneficial for both prevention and management of cardiovascular diseases due to its multi-pronged approach targeting various physiological parameters (9). Hence, this case study was planned to evaluate the effects of integrated yoga and ayurveda approach (Hydayadhara, sun salutation, and MSRT) together with intake of Ayurvedic herbs on ejection fraction of patient with a history of hypertension. During initial evaluation, Ejection fraction and Blood pressure are checked. 
$\mathrm{EF}$ is a key parameter of heart health. It indicates the pumping capacity of the heart which is responsible for supplying oxygenated blood to all the organs of the body. American society of echocardiography guidelines reports that a healthy heart has $55 \%$ or higher ejection fraction, between 50 and $55 \%$ is considered as borderline, whereas if an ejection fraction is below $5 \%$, it indicates inefficiency in the cardiac pumping owing to a weak heart muscle or blockages in the aorta. (10) Therefore, people who have coronary diseases, cardiomyopathy, or hypertension tend to have low ejection fraction. To measure heart function including ejection fraction, Transthoracic echocardiogram (TTE), Myocardial Perfusion Imaging (MPI), and CT Coronary angiogram (CTCA) are commonly used.A normal BP is vital for delivery of blood, nutrients, and hormones to various tissues of the body. As per guidelines from American Heart Association in 2020, the healthy BP is generally stated to be less than $120 / 80 \mathrm{mmHg}$ (Systolic/Diastolic) and 130-139 systolic or/and 80-89 mm $\mathrm{Hg}$ diastolic is considered as hypertension. Recent study suggests that for every $20 \mathrm{mmHg}$ systolic or $10 \mathrm{mmHg}$ diastolic increase in BP, the mortality from ischemic heart disease and stroke doubles (11). Sphygmomanometer is used to measure BP, both Systolic and Diastolic.

Energy level, quality of sleep, and stress level are also important parameters to assess mental health. For this the patient is asked to rate each of the above on a scale of 1 to 10 at each session. 1 being the minimum/lowest and 10 is the maximum/highest.

\section{Case presentation}

The patient was a 60 year-old female with an eight-year history of hypertension controlled on medication as on April $20^{\text {th }}, 2019$. She had an episode of angina coupled with high BP which resulted in myocardial ischemia. The patient presented with complaints of chest pain, breathlessness, sleeping problems, with history of hypertension (on medication). As the patient gave consent, an integration of yoga and ayurveda approach to balance doshas for her overall health was executed.

\section{Recruitment of patient}

The patient, who was self-enrolled in Union Yoga Ayurveda Program in Singapore volunteered to participate in the study. The selection criteria included willingness to participate, EF above $50 \%$, Coronary blockage not more that $60 \%$, exclusion of psychiatric disorders, absence of any other associated disorders and complications and physical ability to be able to do postures. This is a single case study of the short-term effect of hrudaydhara on ejection fraction on a patient having chronic hypertension.

Protocol of integrated yoga and Ayurveda included a combination of hrudaydhara, sun salutation, and MSRT, and this was conducted ten times. Patient had therapy twice a week for the first three weeks and once a week from the fourth week onwards till the end. This integrated yoga and Ayurveda approach was designed to decrease excess kapha and vata and improve cardiovascular function. Energy level was scored at each session and data of BP and ejection fraction were collected at pre and post.

Each therapy session was started with three rounds of sun salutation and followed by hrudaydhara together with MSRT, and concluded by another three rounds of sun salutation. Sun salutation helps warm up the body (12). Hrudaydhara is done to stimulate the chambers of the heart to strengthen the cardiovascular system, with brahmi gritham to improve circulation (13) and ksheerabala 101 to strengthen heart function (14). MSRT is a meditation technique, practiced to calm the mind and reduce stress level by using of mind power and creating certain patterns of vibration associated with resonance (15).

Table 1: Design of study

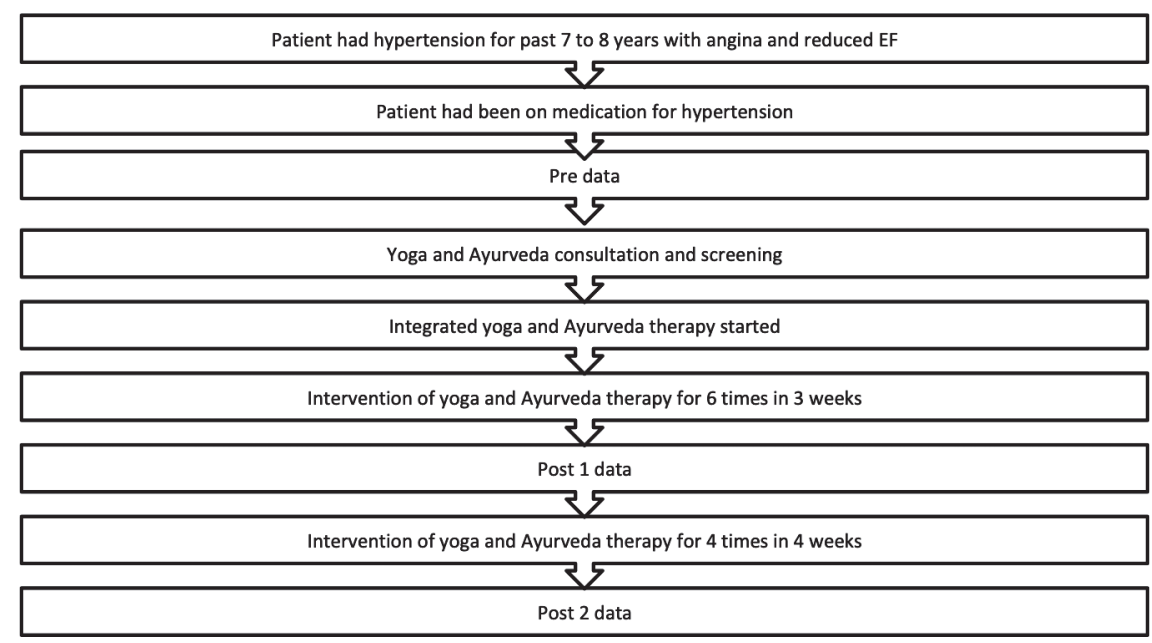

${ }^{*}$ Pre: Before therapy started, Apr $11^{\text {th }}$ in 2019

${ }^{*}$ Post: After $6^{\text {th }}$ session of therapy, May $17^{\text {th }}$ in 2019 
Patient was prescribed Ashwagandha, Liver formula (Liv-52 of Himalaya), Triphala, Arjuna and Arjuna aristha and which was taken every day.

Table 2: Prescribed Ayurvedic herbs and dosages per day

\begin{tabular}{|l|l|c|}
\hline $\begin{array}{l}\text { Name of } \\
\text { herbs }\end{array}$ & $\begin{array}{l}\text { Prescribed dosages } \\
\text { (Morning-Afternoon-Night) }\end{array}$ & $\begin{array}{c}\text { Total dosages } \\
\text { per day }\end{array}$ \\
\hline Ashwaganda & $1,000 \mathrm{mg}-1,000 \mathrm{mg}-1,000 \mathrm{mg}$ & $3,000 \mathrm{mg}$ \\
\hline Liver formula & $250 \mathrm{mg}-0 \mathrm{mg}-500 \mathrm{mg}$ & $500 \mathrm{mg}$ \\
\hline Triphala & $1,000 \mathrm{mg}-500 \mathrm{mg}-1,000 \mathrm{mg}$ & $2,500 \mathrm{mg}$ \\
\hline Arjuna & $500 \mathrm{mg}-500 \mathrm{mg}-500 \mathrm{mg}$ & $1,500 \mathrm{mg}$ \\
\hline Arjuna aristha & $20 \mathrm{ml}-0 \mathrm{ml}-20 \mathrm{ml}$ & $40 \mathrm{ml}$ \\
\hline
\end{tabular}

\section{Discussion}

In Ayurveda, hypertension without specific symptoms in its mild and moderate stages is not considered as a kastha sadhya (difficult to cure) disease because it is attributed to tri-dosha imbalance. (16) As in this case, the patient presented with complaints of chest pain, breathlessness, sleeping problems, with history of hypertension (on medication). As the patient gave consent, an integration of yoga and ayurveda approach to balance doshas for her overall health was executed. Hrudaydhara is beneficial for decreasing avalambaka kapha, removing ama from rasa vaha slotas, rakta vaha srotas and prana vaha slotas for decreasing excess vyana vayu (5).

In order to monitor patient's response to various therapies, Visual analogue scales (VAS) was used. VAS is a key scale used in daily practice by patients and therapist. In this case study, four questions i.e about energy level, chest pain, quality of sleep, and stress level were asked at beginning of each therapy (16). As a result, positive changes were seen in energy level, chest pain, quality of sleep and stress level throughout the course of the therapy. Energy level and stress levels were improved during the sessions, and chest pain was well managed after the sixth session. Also, though the quality of sleep was affected by her working style but it was improved. Also, clinical reports showed improvement of LVEF and normalization of BP. The test before therapy (Pre) was taken on Apr $11^{\text {th }}$ in 2019, and another test after 6th therapy (post) was taken on May $17^{\text {th }}, 2019$.

Table 3: Results per parameters

\begin{tabular}{|l|l|l|c|}
\hline Parameters & Pre & Post & \% of change \\
\hline Energy level & 2 & 7 & $250 \% \uparrow$ \\
\hline Chest pain & 6 & 0 & N/A \\
\hline Quality of sleep & 2 & 7 & $250 \% \uparrow$ \\
\hline Stress level & 8 & 2 & $75 \% \downarrow$ \\
\hline EF & $60 \%$ & $62 \%$ & $3.3 \% \uparrow$ \\
\hline Blood pressure & $180 \mathrm{mmHg}$ & $162 \mathrm{mmHg}$ & $10.0 \% \downarrow$ \\
\hline
\end{tabular}

INTEGRATIVE MEDICINE CASE REPORTS VOLUME 2 NUMBER 2 JULY 2021

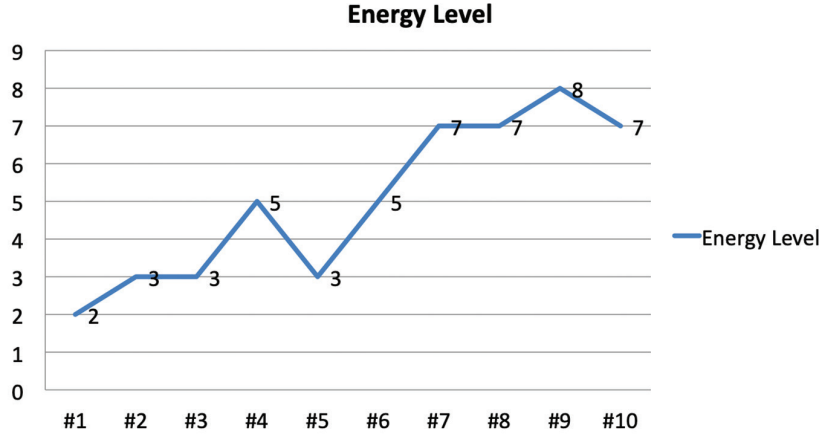

\begin{tabular}{|l|l|l|l|l|l|l|l|l|l|l|}
\hline Number of session & $\# 1$ & $\# 2$ & $\# 3$ & $\# 4$ & $\# 5$ & $\# 6$ & $\# 7$ & $\# 8$ & $\# 9$ & $\# 10$ \\
\hline Energy level & 2 & 3 & 3 & 5 & 3 & 5 & 7 & 7 & 8 & 7 \\
\hline
\end{tabular}

Picture 1: Energy level scale per session

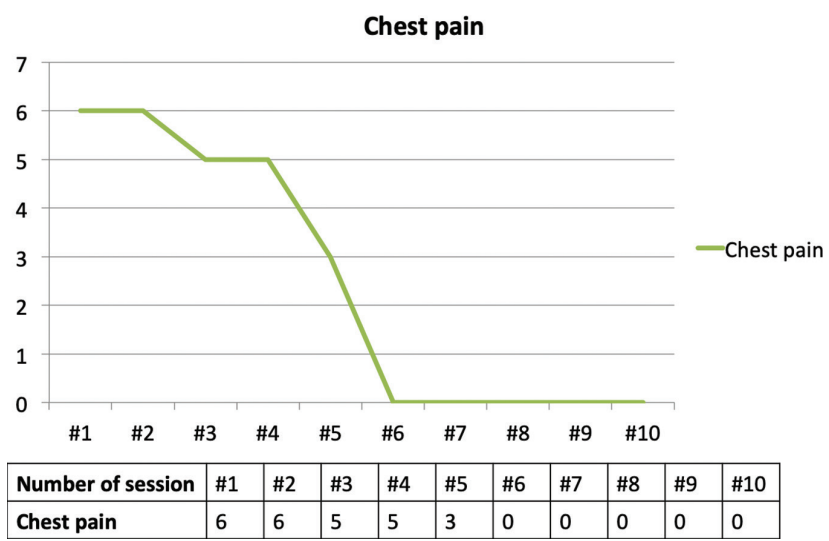

Picture 2: Chest pain scale per session

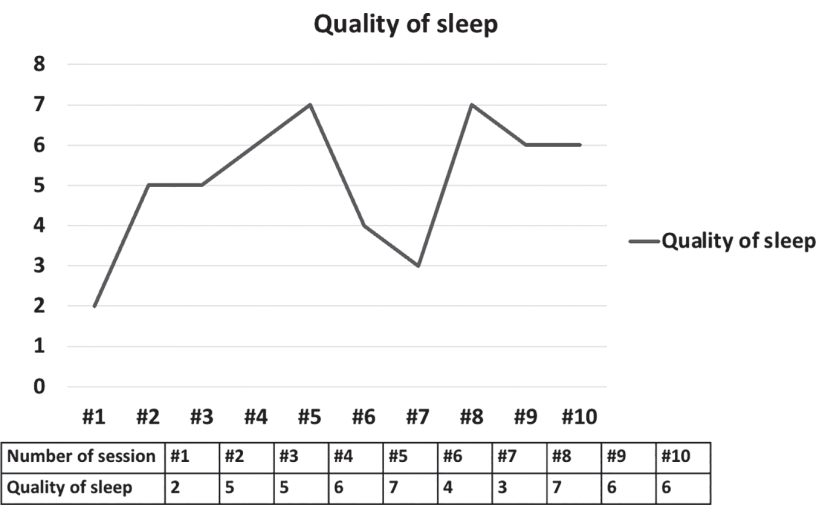

Picture 3: Quality of sleep scale per session

Practices of yoga, like Sun salutation, have been helpful in stabilizing heart rate and permitting variation, and also warming up for burning calories (17). This flexibility in heart variation accommodates the sympathetic nervous system (SNS) to have better adjustment in ejection of blood from the left ventricle to various parts of the body. As different environmental conditions and daily activities demand different levels of blood supply, an improved ejection fraction can help understand heart health. In the current case, even though the patient was on hypertension medication, the blood pressure was fluctuating, with a decreased ejection fraction resulting in difficulty 


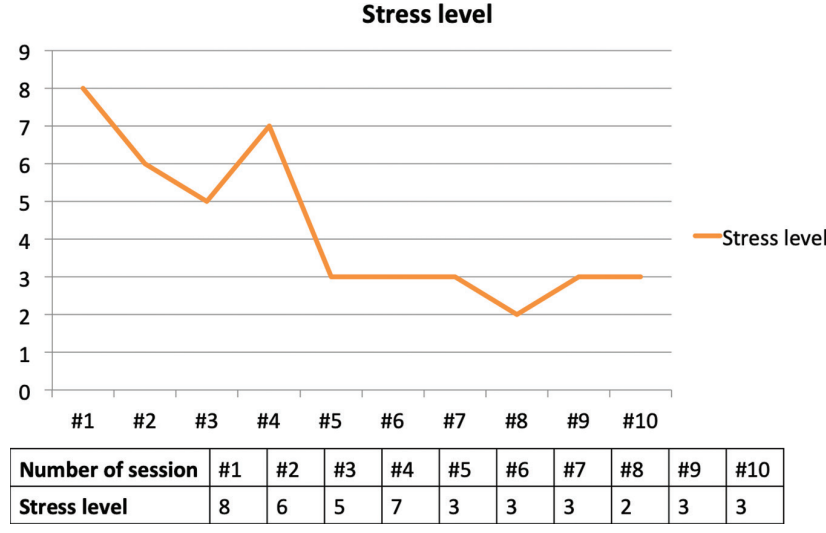

Picture 4: Stress level scale per session
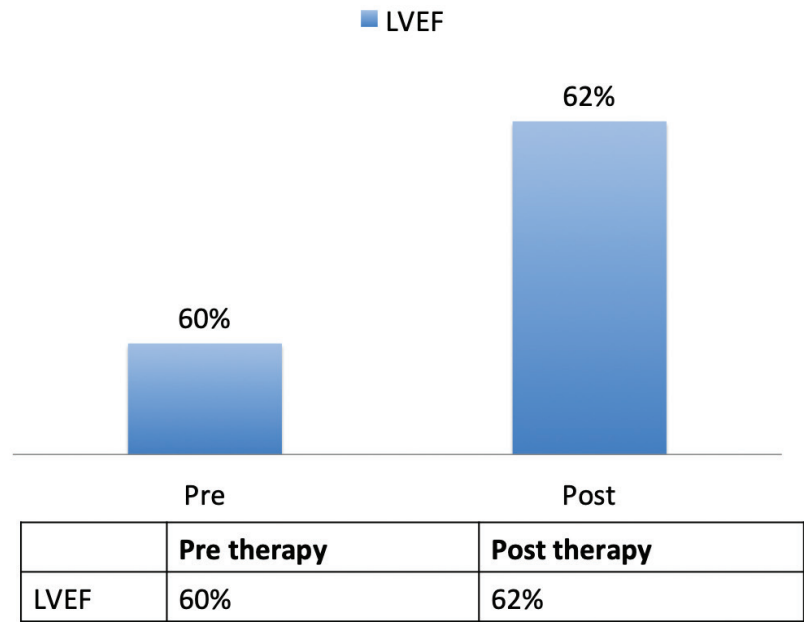

Picture 5: Left ventricular ejection fraction

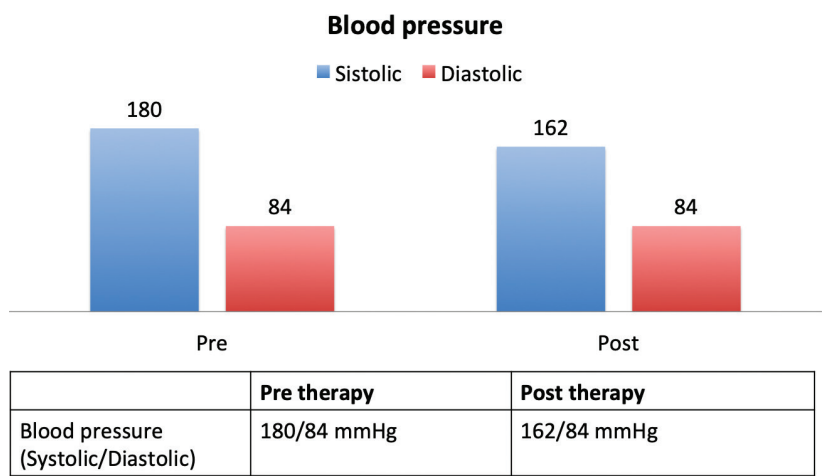

Picture 6: Blood pressure

in breathing along with chest discomfort etc. She underwent conventional investigations to rule out conditions like myocardial infarction and angina, which were found to be absent.

By integrating yoga practices and Ayurveda therapy along with modern medication, the blood pressure was stabilized with an improvement of ejection fraction This resulted in reduced load on the heart and better delivery of oxygenated blood to various tissues. This infers we need more than just medication and exercise for a healthy heart.

The heart has a pacemaker i.e. Sino Atrial (SA) node which sends signals to Atrioventricular nodes (18). With the help of hrudaydhara and MSRT chanting, a relaxing vibration is induced to maintain a healthy rhythm and to control tachycardia. Present study shows that MSRT has positive effects on blood pressure, heart rate, and anxiety in patients with essential hypertension (19). Contrary to the traditional notion of palpitations and breathless being symptoms of old age, they have been found even in younger people owing to risk factors for poor cardiac health. After starting yoga and Ayurveda therapy, it was suggested that symptoms reduced and heart parameters were well stabilized. This concluded that the rhythm of pacemaker and contractions of heart muscles improves after therapy, subject to regular follow up visits and appropriate intervention (7).

To keep the cardiovascular system healthy, Kapha takes important role to be displaced from srotas to allow the vyana vayu and continue its impact on healthy heart. The imbalance of vyana vayu causes arrhythmia and it can create the bigger and various issues (20). Dynamic practices like sun salutation along with hrudaydhara has been useful to do the same which ultimately makes the vyana vayu conduct proper flow of blood to each part of the body and maintaining better health (21). The vyana vayu can be hence compared with connection of SA node and AV node for regular healthy rhythm of the heart and the proper rhythm finally improved ejection fraction. The integration of yoga-ayurveda results to healthy vyana prana, which is improved ejection fraction effects on symptoms like chest pain and uneasiness vanished and sleep or resting quality got better. This allows the parasympathetic nervous system to take over the impact and maintain normalcy.

\section{Limitations}

This modality of treatment cannot be used for emergencies and requires sustained patient compliance and follow-up. Also, only a few studies have been done in this field so far.

\section{Conclusion}

This case study shows that hrudaydhara works to improve ejection fraction. Considering the patient of this case had an 8-year history of hypertension, hrudaydhara is not enough for Prati prasava but integrating yoga and Ayurveda therapy, together with MSRT and sun salutation is necessary for the patient's overall health.

\section{Future implications}

This case study is opening a door for a Randomized controlled trial (RCT) to see if the therapies in the study can be used as a replacement to long term medications.

\section{Acknowledgement}

This case study is made possible through the help and support from family and friends. Our deep sense of gratitude to Union 
Yoga and Ayurveda Center for their active and passive support. Last but not the least we would like to extend our appreciation who could not be mentioned here but played their role to inspire us to complete this work.

\section{Authors contributions}

ST: Led the work from its conception to completion together with diagnosis and prescription of treatment plan with dosage and duration of therapy along with intermediate reviews.

MA: Studied available body of knowledge around the treatment prescribed and compared results from Yoga and Ayurveda therapy treatments also documenting the results and scripting the presis in this case study.

RV: Manuscript editing and writing.

\section{Informed consent}

Yes.

\section{Source of funding}

Nil.

\section{Conflict of interest}

Nil.

Received Date: 16-01-21; Revised Date: 30-03-21

Accepted Date: 13-06-21

\section{References}

1. Cardiovascular diseases (CVDs). (2021). Retrieved 11 March 2020 https://www.who.int/news-room/fact-sheets/detail/cardiovascular-diseases-(cvds)

2. Singapore Statistics - Singapore Heart Foundation. (2021). Retrieved 11 March 2020, https://www.myheart.org.sg/my-heart/heart-statistics/singapore-statistics/

3. Chaturvedi, N. (2003). Ethnic differences in cardiovascular disease. Heart, 89(6), 681-686. doi: 10.1136/heart.89.6.681

4. Sanapeti, V.R., \& Chaganti, S. (2012). Etiopathogenesis of hypertension in ayurveda. International Journal Of Research In Ayurveda And Pharmacy, 3(6), 786-788. doi: 10.7897/2277-4343.03618

5. Menon, M., \& Shukla, A. (2018). Understanding hypertension in the light of Ayurveda. Journal of Ayurveda And Integrative Medicine, 9(4), 302-307. doi: 10.1016/j.jaim.2017.10.004

6. Rohit, S., \& Rahul, M. (2018). Efficacy of heart failure reversal treatment in patients with low ejection fraction. Journal Of Ayurveda And Integrative Medicine, 9(4), 285-289. doi: 10.1016/j.jaim.2017.08.004

7. Sane, R., Aklujkar, A., Patil, A., \& Mandole, R. (2017). Effect of heart failure reversal treatment as add-on therapy in patients with chronic heart failure: A randomized, open-label study. Indian Heart Journal, 69(3), 299-304. doi: 10.1016/j.ihj.2016.10.012
8. Manchanda, S. (2014). Yoga - A promising technique to control cardiovascular disease. Indian Heart Journal, 66(5), 487-489. doi: 10.1016/j. ihj.2014.08.013

9. Patwardhan, B., Mutalik, G., \& Tillu, G. (2015). Integrative Approaches for Health. Burlington: Elsevier Science.

10. Wagholikar, K., Fischer, C., Goodson, A., Herrick, C., Rees, M., \& Toscano, E. et al. (2018). Extraction of Ejection Fraction from Echocardiography Notes for Constructing a Cohort of Patients having Heart Failure with reduced Ejection Fraction (HFrEF). Journal Of Medical Systems, 42(11). doi: 10.1007/s10916-018-1066-7

11. Chobanian, A., Bakris, G., \& Black, H. (2003). The seventh report of the Joint National Committee on prevention, detection, evaluation, and treatment of high blood pressure. The JNC 7 report. ACC Current Journal Review, 12(4), 31-32. doi:10.1016/s1062-1458(03)00270-8

12. Arumugam, S. (2021). Retrieved 12 January 2021; https://www.researchgate.net/publication/273138328_effects_of_suryanamaskar_on_cardio_vascular_and_respiratory_parameters_in_school_students

13. Mishra, D., \& Tubaki, B. R. (2019). Effect of Brahmi vati and Sarpagandha ghana VATI in management of essential Hypertension - a Randomized, double blind, clinical study. Journal of Ayurveda and Integrative Medicine, 10(4), 269-276. doi:10.1016/j.jaim.2017.04.001

14. Madambath, I., Rejitha, S., \& Prathibha, P. (2015). The Ayurvedic drug Ksheerabala (101) Ameliorates alcohol-induced Neurotoxicity by Down-Regulating the expression of transcription factor (NFKB) in rat brain. AYU (An International Quarterly Journal of Research in Ayurveda), 36(3), 323. doi:10.4103/0974-8520.182749

15. Rao, M., Metri, K.G., Raghuram, R., \& Hongasandra, N.R. (2017). Effects of Mind Sound Resonance Technique (Yogic Relaxation) on Psychological States, Sleep Quality, and Cognitive Functions in Female Teachers: A Randomized, Controlled Trial. Advances in Mind- Body Medicine, 31(1), 4-9. https://pubmed.ncbi.nlm.nih.gov/28183071/

16. Klimek, L., Bergmann, K.C., Biedermann, T., Bousquet, J., Hellings, P., Jung, K., Merk, H. et al. (2017) Visual Analogue Scales (Vas): Measuring Instruments for the Documentation of Symptoms and Therapy Monitoring in Cases of Allergic Rhinitis in Everyday Health Care. Allergo Journal International, 26(1), 16-24. https://www.ncbi.nlm.nih.gov/ pmc/articles/PMC5288410/.

17. Mody, B. (2011). Acute effects of Surya Namaskar on the cardiovascular \& metabolic system. Journal of Bodywork and Movement Therapies, 15(3), 343-347. doi: 10.1016/j.jbmt.2010.05.001

18. Christoffels, V., Smits, G., Kispert, A., \& Moorman, A. (2010). Development of the Pacemaker Tissues of the Heart. Circulation Research, 106(2), 240-254. doi: 10.1161/circresaha.109.205419

19. Wang, Y., Metri, K., Singh, A., \& Raghuram, N. (2018). Immediate effect of mind sound resonance technique (MSRT - a yoga-based relaxation technique) on blood pressure, heart rate, and state anxiety in individuals with hypertension: a pilot study. Journal Of Complementary And Integrative Medicine, 17(2). doi: 10.1515/jcim-2017-0177

20. Sane, R., Aklujkar, A., Patil, A., \& Mandole, R. (2017). Effect of heart failure reversal treatment as add-on therapy in patients with chronic heart failure: A randomized, open-label study. Indian Heart Journal, 69(3), 299-304. doi: 10.1016/j.ihj.2016.10.012

21. Singhal, A., \& Gupta, K. (2017). Essential Hypertension - An Ayurvedic Review. Journal of Ayurveda and Integrated Medical Sciences (JAIMS), 2(1). doi: $10.21760 /$ jaims.v2i1.7500 